\title{
QUEM NÃO PINK NÃO FLOYD: VESTÍGIOS DA CEU - CASA DO ESTUDANTE UNIVERSITÁRIO, UFRJ
}

Maria Helena da Fonseca Hermes ${ }^{1}$

\begin{abstract}
Arrive-t-il que la culture défende d'ésthetiser certains objects? Il semble en effet qu'elle ne consacre qu'en excluant, qu'elle ne définisse le bon goût qu'en dénonçant le mauvais, celui qui se trompe d'objet, qui esthétise ce qui ne mérite pas de l'être. Par example le médiocre ou le raté qui encombrent le domaine de l'art. Et 1 urinoir? Duchamp ne s'est pas expliqué sur le sens qu'il donnait à son exhibition: S'agissait-il de tourner endérision la crédulité d'un public prêt a accepter comme art tout ce que se propose un artiste et qu'expose une galerie ?... y a-t-il des limites à l'ésthetisable?
\end{abstract}

Dufrenne, Mikel - Le champ de l'estéthisable

\section{Resumo}

As metodologias do projeto de restauração do conjunto arquitetônico da CEU e a insuficiência de verbas para sua total restauração foram determinantes para considerar as manifestações singulares tratadas aqui ao longo dos amplos caminhos do campo dos registros e da memória, provocando a busca de ampliação destes conceitos para se somar à história do patrimônio edificado. Este trabalho quer apresentar como questionamento a validade da construção de uma proposta de reconhecimento e valoração dos vestígios, desenhos, recortes, colagens, pinturas encontrados na quase totalidade dos espaços e aposentos ocupados nas décadas de 70, 80 e até meados dos 90 pelos estudantes da Casa do Estudante Universitário - CEU, no Flamengo-Rio de Janeiro. Na trajetória da restauração da edificação, vimos escorrer pelos dedos os vestígios de um período que não mereceu nossa atenção, apesar do local de ter se constituído numa referencia cultural e política nas décadas de 70 e 80 . O que define o que é o estetizável?

Palavras-chave: vestígios, memória, análise crítica.

\section{Introdução}

No início eram só rabiscos, escombros, desordem e sujeira. O prédio, em completo abandono em seus mais de 5 mil metros quadrados, encerrava histórias e mais estórias em sua longa jornada como abrigo. Escrevendo aqui estas poucas linhas meio sem rumo, depois de se passado tanto tempo, constato ainda a impressão de ausências na experiência sentida e pressentida, por meio de uma outra experiência, aquela da convivência diária de quase três anos trabalhando dentro do monumento arquitetônico tombado, quase que completamente abandonado. Mas o momento era de novas e alvissareiras providencias; encontrávamos em 1997, prestes a dar início às primeiras reformas nas fachadas daquela construção. Muito tempo, algumas obras e muito trabalho decorreram em alguns anos, sempre com foco na obtenção de recursos públicos para a restauração e revitalização do monumento. Após diversas tentativas que resultaram em sucessivos fracassos, tendo sido alegada a ausência de previsão orçamentária dentro da UFRJ para tal monta de recursos, vislumbrou-se uma possibilidade para viabilizar o sonho, via a obtenção de renuncia fiscal federal, pela lei Rouanet do MINC. Estávamos em 1999 e fazia-se relevante compreender da importância da revitalização do imóvel para sua re-introdução na vida carioca, como a

${ }^{1}$ Arquiteta UFRJ e Mestranda PPGAV/EBA/UFRJ. 
alegação maior para viabilizar sua regulamentação sob tal legislação. O projeto foi aprovado em agosto de 2000.

Tombado como a CEU - Casa do Estudante Universitário em 1989, em nenhum momento do processo elaboração de um novo uso pela UFRJ foi considerada, mesmo que remotamente, a possibilidade do imóvel retornar ao uso de Casa do Estudante, nem para alunos da UFRJ. As possibilidades sugeridas e tentadas em diferentes discussões e alguns croquis se resumiram entre a proposta de instalação de uma Incubadora de Artes - com a criação de ateliês e salões de mostras, um Hotel da UFRJ para professores visitantes, instalações para a Faculdade de Administração e Ciências Contábeis da UFRJ - instalada em prédio histórico no Campus da Praia Vermelha, a um projeto multidisciplinar que pretendia reunir sob mesma edificação desde unidades de pós-graduação, cursos de extensão, museu de energia, cursos tipo MBAs em parcerias do Instituto de Economia e o setor publico e privado de energia.

\section{$1 \mathrm{Um}$ pouco do muito que ainda há para investigar}

Nada ainda se sabe do uso deste conjunto arquitetônico, quanto ao período de sua existência enquanto Hotel, função mesma de sua construção em 1922, de um complexo balneário num Rio de Janeiro, em processo de nova urbanização, à moda européia.

Não foram pesquisados registros referentes ao prédio durante sua destinação como a antiga Casa do Estudante Universitário, ou melhor, não se havia demonstrado um grande interesse em considerar informações deste período, em virtude daquelas que se referiam à destruição e maus tratos ao prédio em seu ultimo período como CEU.

Assim, durante o período decorrido desde a formatação do projeto cultural para o apoio pela lei Rouanet, optou-se por suprimir esta parte da história, imaginando-se talvez que houvesse uma prevalência de aspectos negativos em sua constituição.

As diretrizes da fundação gestora do projeto, optando por iniciar as obras de restauração pelo prédio menor, denominado como prédio anexo a partir de dezembro de 2001, direcionaram os trabalhos de registros de restauração de arquitetura nesta unidade. Os registros encontrados do uso anterior, como CEU, deveriam ser retirados. Atualmente sabe-se que o prédio Anexo foi construído para ser um Restaurante, por iniciativa da Prefeitura da Cidade.

O prédio principal ou o Hotel propriamente dito, com dimensão quatro vezes superior ao prédio anexo, que compreende, além de outros salões mais de 100 quartos, aposentos usados pelos estudantes, pelas enfermeiras e pelo antigo Hotel, não fizeram parte da primeira etapa de obras. Este prédio foi construído para ser o Hotel balneáreo, num complexo que incluía a construção de cabines de banho sob o leito da antiga Avenida do Contorno, que logo após foi denominada, como até hoje, de Av. Rui Barbosa.

Esta edificação maior permaneceu sem obras e quase abandonada, apesar do uso de parte de seu primeiro pavimento pelos escritórios da construtora contratada e do grupo técnico de arquitetura do Projeto de Restauro RB 762 UFRJ. Esta situação foi determinante para considerar as manifestações singulares de que este trabalho vem tratar, no campo dos registros e da memória, ampliando este conceito ao se somar à história deste patrimônio edificado.

O trabalho quer apresentar como questionamento a validade da construção de uma proposta de reconhecimento e valoração dos vestígios encontrados na quase totalidade dos espaços e aposentos ocupados nas décadas de 70, 80 e até meados dos 90 pelos estudantes da CEU, no prédio principal. Nesta trajetória, vemos escorrer pelos dedos os registros de 
um período que não mereceu nossa atenção, apesar do local de ter se constituído numa referencia cultural e política nas décadas de 70 e 80.

\section{Vestígios - valoração e simbologia}

Rascunhos, desenhos, pinturas, frases, versos, fragmentos - recortes de jornal. No escuro do abandono daquela construção, testemunhos de um tempo passado restam despercebidos como os vestígios de uma história não divulgada, momentos que não mais se agrupam a não ser nas lembranças daqueles que viveram estas hoje - lembranças. No meu entendimento, os vestígios podem representar um mundo que existiu e que era vivo. Teriam eles a força de signos para aqueles grupos que lá vivenciaram suas experiências? Aquele espaço abrigou vidas e vivências, crenças e mitos, realidades e sonhos. Conquanto nunca tenham sido sequer considerados como objetos dignos de mover a percepção estética e menos ainda como objetos passíveis de estetização, os vestígios encontrados situam-se num limbo de indefinição: por guardarem o pressuposto de nunca haver correspondido ao desejo real de se apresentar como obras de arte ou por não guardarem enquanto objetos de contemplação os valores correspondentes àquele grau diferencial da escala que permitiria sua distinção e reconhecimento como belo.

Usando a referencia de Dufrenne, em 'Não há um objeto estético senão para um sujeito estetizante." ou ainda que "A estetização é um ato de uma percepção que se liga à aparência do objeto e que o percebe como sensivel."(1) cabe a pergunta de que em que grau este tipo de "manifestação sensível" poderá vir a ser percebida, se vai se esvaecer e se perder durante e ao término dos serviços de restauro? Para qual dos momentos vividos nos é dada a autorização de retroceder no tempo, naquilo que se propõe a um " resgate" e revalorização? Como sublimar uma parte ou seu todo, sem considerar uma discussão e uma forma de preservação que propicie revisões na adoção de valores estéticos?

Temas como estes integram e realimentam as diretrizes de conservação e restauração do patrimônio construído, no documento conhecido como Carta de Veneza, para a conservação de monumentos:

Artigo 1: A noção de monumento histórico compreende, além da obra arquitetônica em si, os sítios urbanos e rurais, testemunhos de uma civilização determinada de uma evolução significativa, e de fato histórico. Compreende as grandes criações, e também as obras modestas, que, através do tempo, adquiriram valor cultural significativo" $(2)^{2}$

Artigo 11: Os acréscimos à construção de um monumento são marcas respeitáveis de todas as épocas, e devem permanecer, uma vez que a unidade do estilo não constitui a meta final da restauração. Quando em um edifício vários acréscimos se superpõem, o resgate de um estágio subjacente não se justifica, senão excepcionalmente, e, sob a condição de que os elementos retirados não sejam representativos, a composição descoberta deve constituir testemunho de grande valor histórico, arqueológico ou estético, e seu estado de conservação considerado suficiente. O julgamento sobre o valor dos elementos em questão e a decisão das eliminações a operar não poderão depender somente do autor do projeto. $(2)^{3}$

2 (1) DUFRENNE, Mikel. Le champ de l'estéthisable.

3 (2) CARTA DE VENEZA CARTA INTERNACIONAL SOBRE CONSERVAÇÃO E RESTAURAÇÃO

DE MONUMENTOS E SÍTIOS. II Congresso Internacional de Arquitetos e Técnicos dos Monumentos Históricos e ICOMOS - Conselho Internacional de Monumentos e Sitio. Veneza;1964 
Tais dúvidas não pressupõem que estes vestígios possam encerrar em si a representação global dos momentos vivenciados por aqueles grupos cariocas, mas, em contrapartida, ignorá-los, seria como amortecer a validade daquelas vivencias, confundidas por demasiada descrença nos objetos símbolo de um momento político. Considerando ainda demasiados estreitos e canônicos os limites da representação pictórica das representações artísticas, decidi me embrenhar para propor a exposição das imagens registradas, quase como uma imposição pessoal, apesar de haver trabalhado arduamente à frente de conseguir resultados para a consecução do projeto arquitetônico, formatação deste na lei cultural de restauração do patrimônio, sem me aperceber naquele momento na conseqüente destruição destes vestígios.

A questão desses vestígios guarda algumas similaridades, porém não identidade, com os traços que encontramos pelas ruas em pichações de muros e grafites em equipamentos urbanos. Ambas clamam por serem percebidas, revelando e externando seus criadores, nas pichações aflorando o inconsciente coletivo e nesses vestígios, os resultados do consciente daquele tipo de coletivo.

O respaldo que me orienta nestas afirmativas pode ser objeto de outra pesquisa que dê conta do período que a CEU abrigou a Casa do Estudante Universitário, desde a atuação e a produção de peças teatrais, musica e festividades, produção cinematográfica, até o abrigo de grupos e organizações para manifestações de cunho social e político.

Como não fazer menção a este período e de alguma forma se sensibilizar com o que ficou registrado naquelas paredes?

Por ser possível expor justificativas para tal valorização buscando as referências de experiência estética na representação emotiva, crê que a valoração desta experiência estética poderia estar adormecida enquanto aguardava o reconhecimento formal. E essa possibilidade se esgotou no tempo e nos faz rever, pensar e repensar. O que é o reconhecimento formal, senão uma atribuição de valoração, atrelada aos julgamentos individuais? "Onde bá adesão psicológica encontramos beleza e arte. Em uma palavra: toda experiência é em maior ou menor grau experiência estética." $\left.{ }^{4}\right)$

$\mathrm{Da}$ avaliação do material exposto, percebe-se a natureza do universo que está contemplado naqueles momentos, vivenciados naquele local naqueles grupos, ainda que sem conhecimento dos fatos em si. Este conhecimento foi sendo percebido quando em contato com estas marcas - que aqui estão designados como vestígios que, como se houvessem cristalizado de alguma forma se harmonizam com outros conhecimentos do bem. A valoração passa a ser então de outra natureza, não como um reconhecimento de qualidades pictóricas e gráficas objetivas ou de uma reação subjetiva provocada pelo objeto, mas de uma ligação mais que presente, latente, porém não direta.

\section{$3 \mathbf{O}$ avesso se encontra na arte}

Considerações sobre atitude estética descritas no capítulo anterior encontraram sua complementaridade, como que numa outra forma de tradução, por meio de uma demanda proposta pelo conhecido e talentoso artista plástico brasileiro Daniel Senise, “é um pintor que pratica e paradoxalmente se recusa a pintar, preferindo se colocar como alguém interessado em expandir a compreensão da pintura como superficie." (7)

Sem assimilar como objetos estetizáveis os vestígios encontrados nas paredes da CEU, objeto da apresentação e questionamento deste trabalho, conseguiu nos surpreender

4 Tagliabue, Guido. La experiência estética: uma investigación. Buenos Aires; Ed. Losada, 19_? 
enxergando no meio dos escombros, desordem e sujeira daqueles mesmos aposentos, uma nova fonte de recursos primários para a elaboração de seu trabalho, já consagrado. Afinal, retomando M Ponty, tudo se constitui do mesmo estofo, e assim segue.

Trata-se da remoção de resíduos, poeira e sujidades dos pisos tabuados de madeira - frisos, por meio de uma solução impregnada no tecido/canvas. Desta aplicação temos como resultado um decalque ou uma impressão, uma nova revelação, por meio dos pedaços, tiras, cortes e recortes que são criados e recriados, cortados e remontados para nos revelar um outro desenho que o artista vai digerindo e reinterpretando, até criar sua obra.

Após a leitura do livro The piano factory, de Daniel Senise, onde os textos de Agnaldo Farias e Alexandre Mello descrevem os processos de trabalho do artista e são apresentados mais de 20 trabalhos executados sob esta mesma técnica de "acrílica em colagem sobre madeira", solicitamos que fosse feito inicialmente um teste em uma parte do piso mais desgastado, antes de liberar os espaços para que fosse executada esta remoção ou "limpeza". Verificamos que a remoção de resíduos e sujeira realmente não traria nenhum prejuízo à madeira que compõe os pisos e nem deixaria resíduos indesejáveis no tabuado, mas ao contrário e então disponibilizamos os espaços para que fossem iniciados os primeiros trabalhos. Durante a execução do processo dos "sudários", quaisquer temores iniciais se esvaeceram ao perceber que a técnica de "limpeza" para retirada do material primário, contribuía para não apenas para a limpeza do prédio, mas inclusive auxiliando nossa visualização para elaborar os diagnósticos dos levantamentos métricos, identificação das patologias e estado de conservação do prédio.

\section{Os fios condutores ao pensamento de Merleau Ponty}

Como por um acaso, o processo de recriação dos espaços em sua representação pictórica criou pontes para os vestígios remanescentes da CEU representados nas paredes. É como se um processo legitimasse os direitos do outro e assim, ambos garantiriam suas longevas e distantes significações. Todos, portanto, se creditaram em seus direitos de vir à tona, dizendo alguma coisa dos processos de vida vivenciados naqueles espaços.

A re-interpretação da sensação de validade daqueles signos, já havia de muito penetrado em nosso espírito, mas nos faltava clareza para enxergá-los de dentro para fora, talvez regurgita-los para que pudessem ser entendidos. É nesse sentido que também encontrei as pontes entre ambas as situações descritas e uma situação vivenciada no sentido fenomenológico, no sentido de quando nos é colocado que as coisas já estão lá, latentes e precisam ser descobertas, como a mão que se toca, o corpo que se toca, o olho que vê e que enxerga aquilo que vê, e quando deixamos aflorar nosso sentir no que já está lá, antes, e que se renova no pensar e sentir a coisa mesma.

Neste sentido e no meu entendimento, os matizes do olhar fenomenológico vêm abraçar as descrições que tentativamente me esforcei por transmitir neste trabalho.

\section{Referencias Bibliográficas}

DUFRENNE, Mikel. Le champ de l'estéthisable.

PONTY, Merleau. Vida e Obra.: A linguagem indireta e as vozes do silencio. São Paulo; Abril Cultural, 1980

REIS, Engo José de Oliveira. O Rio de Janeiro e seus prefeitos Evolução urbanística da cidade. Rio de Janeiro: Prefeitura Municipal da cidade do Rio de Janeiro, 1977 
SAMPAIO, Carlos. Memória histórica: obras da Prefeitura do Rio de Janeiro: 8 de junbo de 1920 a 15 de novembro de 1922. Lisboa: Lúmen, 1924

SENISE, Daniel. The piano factory. São Paulo; Andrea Jacobsson , 2002

TAGLIABUE, Guido. La experiência estética: uma investigación. Buenos Aires; Ed. Losada, 19_?

CARTA DE VENEZA CARTA INTERNACIONAL SOBRE CONSERVAÇÃO E RESTAURAÇÃO DE MONUMENTOS E SÍTIOS. II Congresso Internacional de Arquitetos e Técnicos dos Monumentos Históricos e ICOMOS - Conselho Internacional de Monumentos e Sitio. Veneza;1964

HERMES, Maria Helena e FERRAZ, João. Projeto de Restauração e Uso do Hotel Sete de Setembro. UFRJ/Eletrobrás, 1999 